\title{
Psychosocial and Educational Problems for Undergraduate University Nursing Students
}

\author{
Hanan Ebrahim Abd El Aziz Rady ${ }^{1}$, Lamiaa Ahmed El-Sayed ${ }^{2}$ \\ ${ }^{1}$ Mental Health Nursing Department, Faculty of Nursing, Cairo University, Faculty of Nursing, Hail University KSA, Cairo, Egypt \\ ${ }^{2}$ Pediatric Nursing, Faculty of Nursing, Ain-Shams University, Faculty of Nursing, Umm Al-Qura University KSA, Cairo, Egypt
}

Email address:

hanan_ebr2014@yahoo.com (H. E. A. E. A. Rady)

\section{To cite this article:}

Hanan Ebrahim Abd El Aziz Rady, Lamiaa Ahmed El-Sayed. Psychosocial and Educational Problems for Undergraduate University Nursing Students. Psychology and Behavioral Sciences. Vol. 4, No. 3, 2015, pp. 116-124. doi: 10.11648/j.pbs.20150403.15

\begin{abstract}
University students face numerous stressors in addition to academic demands that contribute to the development of mental health problems. These include developmental challenges, increased freedoms, decision making, challenging family beliefs by engaging in risky behaviors', or pressure to do well. Aim The study aimed to determine psychosocial and educational problems for undergraduate university students design, A descriptive exploratory design was utilized in this study, Setting The study was carried out for undergraduate nursing students at faculty of nursing. Cairo university. Subject: A convenient sample composed of 240 undergraduate students. Instruments: first structured questionnaire include Socio-demographic characteristics including students age, sex, academic year. Second, Kessler Psychological Distress Scale It was used to measure of students distress social, psychological and educational problems. Results: It was revealed that females are more likely to have higher level of psychological distress than male students, there was statistically significant difference between level of psychological distress and gender conclusion: undergraduate nursing students have educational, social problems and psychological distress in addition a lot of psychosocial problems as anxiety, depression, academic problems. Recommendations: Particular attention must be given to barriers which prevent faculty nursing students from educational achievement and early interventions to prevent the development of psychological problems for university students.
\end{abstract}

Keywords: University Nursing Students, Psychosocial Problems, Educational Problem

\section{Introduction}

College is a new special period and exciting time for students during which students are mature physically and their views towards life and world are not stable enough. Though they don't have enough experience with particular self-indulgence and confusion, they may have various ambivalences easily. (Tao, Dong, Pratt, Hunsberger, \& Pancer 2007). Students growing opportunities available in a college environment may lead to unhealthy levels of stress which hinder students' abilities to socialize and achieve their academic goals. Recognizing the sources of stress is important in preventing it from becoming unmanageable or debilitating (Rob Callahan, 2011).

University students face numerous stressors and academic demands as study, family and work commitments which contribute to exacerbation of mental health problems. Developmental challenges including increased freedoms, decision making, challenging family beliefs engaging in risky behaviors, or pressure to do well. (Kadison \& DiGeronimo, 2004)

Interpersonal relationship among university students involves teacher-student relationship, student-student relationship, roommate relationship, love relationship. Communication ability for the faculty nurses students is a direct influential factor in their college lives and important factor for their development prospect. Facing students and teachers who have different life styles, values, financial conditions, interests and characters, loneliness and depression may come into being among students if lacking interpersonal communication tips or having communication barrier may lead to serious psychological crisis (Gurung, 2006). Relationships with friends and significant others can be stressful, because they're threatened by external sources of stress. (Rob Callahan, 2011). Poor academic performance leads to the threat of failure and expulsion, a large contribution to student stress levels. One of the side effects of this kind of stress is depression, which can lead to absenteeism or feelings of hopelessness that interfere with 
effective study habits and then further weaken academic achievement (Lakey \& Cohen, 2000) (Rob Callahan, 2011)..

University students are special in psychological status. They grow up in specific environment and change their fate by studying hard. For them, normal study or living expenses cannot be guaranteed and interpersonal relationship appears to be difficult, which makes them feel inferior, anxious, gloomy, self-enclosed, extreme, jealous, self-condemned and sensitive. These psychological barriers come into being and pile up in a long period and lead to psychological crisis (Dollete, Steese, Phillips \& Matthews, 2004).

College students are at a critical period where they will enter adulthood. They are expected to be the elites in the society. Thus, they should enhance their stress management abilities so as to live a healthy life after entering the society. They need to not only adapt themselves to the new life and new environment but also be familiar with many new people, events, and things. Therefore, understanding the sources of stress among them and how they can cope with the stress is very important Abebe (2001) Ministry of Education (2007),

Most students are less competent in interpersonal relationship due to the lack of social interaction before college life. Now it is an important issue for the undergraduates to get on well with other students and build up harmonious relations with them. Due to the difference of each student's attitude and personality, as well as isolation, timidity, sensitiveness and impulse, it is inevitable for them to have various difficulties, and feel confused, nervous, pressed, lonely and unsafe, even have various crises (Lakey \& Cohen, 2000).

Most of the university students were outstanding in their high school and now lose superiority against the numerous rivals in colleges. This competition might lead to sense of loss, serious psychological conflict, inferiority and disappointment for discouragement in study. On the other side, many students failed to choose a specialty based on their interest, even far from their dreams and deviates too much from their future competition and lost interest and motives in their specialties (Calvete, \& Connor-Smith, 2006).

Interpersonal obstacles are the most common psychological barrier among college students. Because many people only have one child, which grow up in love, and there is less communication around us, which make them lack direct contact and adjustment with contemporaries that. produce some frictions lead to have certain social fear, such as fear to contact with people, afraid to speak in public (Eskin, 2003).

Intimacy with parents, as well as parental support and guidance are significant determinants of adolescent adjustment. Parental warmth/involvement, psychological autonomy-granting, and behavioral control/monitoring, are associated with security of attachment in late childhood and early adolescence that contribute to good psychosocial, academic and behavioral adjustment (Villanova and Bownas, 2008). Parent-teen connectedness has been linked to a wide variety of outcomes including mental health (depression, suicide, adjustment, identity), personal traits (self-confidence, coping skills, motivation, overall wellbeing), and social skills including the quality and stability of peer and intimate relationships

young adult who live with their parents are less likely to have emotional problems and their behavior is more likely to be under their parents' control .Secure attachment during adolescence is related to fewer mental health problems, including lower levels of depression, anxiety and feelings of personal inadequacy (Kadison \& DiGeronimo, 2004). Social support helps the college students to lessen depression, anxiety, , stress, help the students manage, help students to cope with everyday life stressor, lighten the burden of academic workload and lessen their psychological problems among students. Without enough support from family and friends, they would be in trouble and are vulnerable to depression, stress and anxiety Elliot and Gramling (1990)\& Dollete et al. (2004). .

\section{Significance of the Study}

Performance in academic life demands all aspects of wellbeing include physical well-being, social well-being, and emotional, spiritual and psychological wellbeing. Students who are physically and psychologically stable are expected to perform better compared to those who are not physically, mentally and psychologically fit. In other words, those who are experiencing psychological problems such as depression, anxiety and stress may face problems in managing their academic performance. Psychological stability is indeed an important predictor that could contribute to high academic achievement. Hence, it is very much crucial determine psychosocial and educational problems for undergraduate university nursing students

\section{Methods}

This study was aimed to determine psychosocial and educational problems for undergraduate university nursing students at the faculty of nursing, Cairo University.

\subsection{Research Design}

A descriptive exploratory design was utilized in this study.

\subsection{Research Setting}

The study was carried out at Cairo University for both male and female section, nursing students in the faculty of nursing.

\subsection{Research Subject}

A Convenient sample was composed of 240 undergraduate male and female nursing students from, second, third and fourth years at the faculty of nursing from the previous mention setting.

\subsection{Instruments}

Two tools were used for data collection includes: 
1- First part: Self- administered questionnaire it composed of two parts:

First part: Socio-Demographic characteristics:

It includes information about students such as, age, academic year, living arrangement, hobbies .interest, academic achievement in previous year, family size\& order in family etc...

Second parts: Questionnaire developed by the researcher it was used to assess social, ethical, psychological and education problems among faculty nursing students. It was consists of three items:

1-Question's for social and ethical problems it was composed of (12) questions which focused on relation with parents and colleges, social relation with others the answer was ranged between yes and no

2- Question's for psychological problems it was composed of(14) questions which focused on student decision regarding psychological problems, students reactions towards psychological problems, students self-confidences, fluctuation of mood and feelings towards futures

3- Question's for educational problems it was composed of (23) questions which focused on problems related to different topics, academic achievement, role of academic advisors, and nature of syllabus

translation and back translation.

2-Second tools was Kessler Psychological Distress Scale (K10)It was adopted from (Kessler. R \& Mroczek. D .1994) used to measure anxiety and depression this scale was composed of 10-item. Each question about the level of anxiety and depressive symptoms a nursing student may have experienced in the most recent four-week period. each has a five-level response scale. Ten questions on non-specific psychological distress and the level of anxiety and depressive symptoms for a nursing students that may have experienced in the most recent four-week period. Ten questions are include :did you feel tired out for no good reasons?, did you feel nervous? did you feel so nervous that nothing could calm you down?, did you feel hopeless?, did you feel restless or fidgety?, did you feel so restless that you could not sit still?, Did you feel depressed?, did you feel that everything was an effort?. Did you feel so sad that nothing could cheer you up?, ten question is did you feel worthless?

The response values of five-level response scale categories which include: all of the time(5),most of the time(4),some of the time(3),A little of the time(2) and none of the time(1).

Scoring system: Total score was ranged from 10 to 50 .

$30-50$ indicate high risk of anxiety or depressive disorder. 16-29 moderate risk of anxiety.10-15 low risk and are likely to be well

\subsection{Ethical Consideration}

Official permissions was obtained from the dean of the faculty of nursing and also from nursing students for their acceptance and cooperation. The nature and the aim of the study were explained to each member of the participants. Oral consent was obtained from all participants .Tools utilized for data collections were explained for the subjects
Participants were assured that all their data are highly confidential, anonymity .

\subsection{Administrative Designs}

Before conducting the study the researchers review related literatures using available textbooks, journals articles, and magazines that help to gather enough information from the both national and international articles. The tools of data collection, self-administered questionnaire and Kessler Psychological Distress Scale (K10) were tested for validity by giving the tools to five expertise's in the field to review it.

\subsection{Field Work}

The actual field work was carried out throughout first term from the beginning of October to the end of January 2014. The investigators were available for 2 days/week, in the previously mentioned study settings. The tools were filled by the researchers through self-administered questionnaire. The average time needed for completion of the interview was around 15-20 minutes.

\subsection{Pilot Study}

It was carried out on $10 \%$ of the study subjects to test the clarity, validity and reliability of the study tools. The subjects involved in the pilot study were excluded from the study and the necessary modifications were done

\subsection{Statistical Analysis}

Descriptive statistics for the frequency, all the analysis were performed Using SPSS package version 20.A probability level $<0.05$ is statistical significance. Statistical tests used to investigate association or significant relation between Psychological distress scale (PDS) (categorical ordinal) which was considered as a dependent variable and socio-demographic variables. Univariate analysis was done using X2 (Pearson Chi-Square) with Cramer's V tests for nominal categorical variables, and Kendall's tau-b with Cramer's V tests for ordinal categorical variables, while one way ANOVA were used for continuous variables. In addition, another statistical analysis used psychological problems (continuous) as a dependent variable and socio-demographic data as independent variables using one way ANOVA.

\section{Results}

As shown in table (1 )that $40 \%$ of the studied sample were from third year while the others(36.7\%)second year and $(23.3 \%)$ from fourth year, in relation to course failure ,more than fifth percent of the studied sample had previous course failure regarding residency more than third percent of the studied sample were from rural areas, while more than sixty percent of them from urban regarding living with families more than fifth percent of them doesn't live with their families as regards (9.6\%) live with Relatives(5.4\%) live with their Colleagues and (5.8\%)of them live alone in relation to parent status the results revealed that ,more than 
three quarters of the studied sample (77.5\%)of them their families live together, while more than fifth of them divorced $(8.8 \%)$ and $(13.8 \%)$ one was widowed. Students mean and standard deviation for age was21.87 \pm 3.27 .

Table 1. Demographic Characteristics of the Nursing Students $(n=240)$.

\begin{tabular}{|c|c|c|}
\hline $\begin{array}{l}\text { Students Demographic } \\
\text { Characteristics }\end{array}$ & N Frequency & (Percentage) $(\%)$ \\
\hline \multicolumn{3}{|l|}{ Gender } \\
\hline Male & 120 & $(50 \%)$ \\
\hline Female & 120 & $(50 \%)$ \\
\hline \multicolumn{3}{|l|}{ Academic year } \\
\hline 2nd year & 88 & $(36.7 \%)$ \\
\hline 3rd year & 96 & $(40 \%)$ \\
\hline 4 th year & 56 & $(23.3 \%)$ \\
\hline \multicolumn{3}{|l|}{ Course Failure } \\
\hline Yes & 50 & $(20.8 \%)$ \\
\hline No & 190 & $(79.2 \%)$ \\
\hline \multicolumn{3}{|c|}{$\begin{array}{l}\text { House Living/persons living with } \\
\text { the student }\end{array}$} \\
\hline Family & 187 & $(77.9 \%)$ \\
\hline Relatives & 23 & $(9.6 \%)$ \\
\hline Colleagues & 13 & $(5.4 \%)$ \\
\hline Alone & 14 & $(5.8 \%)$ \\
\hline Other & 3 & $(1.3 \%)$ \\
\hline \multicolumn{3}{|l|}{ Marital Status } \\
\hline Single & 200 & $(83.5 \%)$ \\
\hline Married & 37 & $(15.4 \%)$ \\
\hline Divorced & 3 & $(1.3 \%)$ \\
\hline \multicolumn{3}{|l|}{ Number of Children } \\
\hline No children & 100 & $(41.7 \%)$ \\
\hline $1->3$ & 136 & $(56.7 .6 \%)$ \\
\hline$<3$ children & 4 & $1.6 \%)$ \\
\hline \multicolumn{3}{|c|}{ Family Information/Parents Status } \\
\hline Together & 186 & $(77.5 \%)$ \\
\hline Divorced & 21 & $(8.8 \%)$ \\
\hline One Widowed & 33 & $(13.8 \%)$ \\
\hline \multicolumn{3}{|c|}{ Number of Family Members } \\
\hline $2-<4$ & 35 & $(14.6 \%)$ \\
\hline $4-<8$ & 103 & $(42.9 \%)$ \\
\hline$>8$ & 102 & $(42.5 \%)$ \\
\hline \multicolumn{3}{|c|}{ Cumulative (Score) Average } \\
\hline Excellent & 42 & $(17.5 \%)$ \\
\hline Very good & 76 & $(31.7 \%)$ \\
\hline Good & 75 & $(31.3 \%)$ \\
\hline Fair & 47 & $(19.6 \%)$ \\
\hline
\end{tabular}

Table 2. Frequencies and Percentage of Nursing Students according to Psychological Distress Scale level (PDS) $(n=240)$.

\begin{tabular}{lll}
\hline Levels of PDS & NFrequency & Percentage(\%) \\
\hline Low (10-19) & 118 & $49.2 \%$ \\
Moderate (20-24) & 58 & $24.2 \%$ \\
High (25-29) & 28 & $11.7 \%$ \\
Very High (30-50) & 36 & $15.0 \%$ \\
Mean \pm SD & $21.10 \pm 7.772$ & \\
\hline
\end{tabular}

Table (2) shows the prevalence of four levels of psychological distress among students; that half of the students $49.4 \%$ (118) have low level of psychological distress, while quadrant of them $24.2 \%$ (58) have moderate level of psychological distress, few $11.7 \%$ (28) have high level of psychological distress, and a few 15\% (36) have very high level of psychological distress. In which the overall psychological distress level was 21.10 7.772 (Mean\& SD) on scale from 10 to 50, which is considered moderate level.

Table (3) demonstrates the prevalence of social problem items among students; it was found that students have Frankness with their parents $35.8 \%$ followed by difficult to find a faithful friend $25.4 \%$ while $20 \%$ of them suffering from hard parent's duties and $14.6 \%$ find difficulty in building relationship with other colleges, while overall social problems demonstrated as $1.81 \pm 2.154$ (Mean\& SD) on scale from 0 to 12 .

Table 3. Prevalence of Social Problem as Perceived by Nursing Students ( $n$ $=240$ ).

\begin{tabular}{lll}
\hline Social Problems & N (\%)Frequency & (Percentage) \% \\
\hline 1. Frankness parents & 86 & $(35.8)$ \\
2. Hassle colleagues & 23 & $(9.6)$ \\
3. Law Compliance & 43 & $(17.9)$ \\
4. Building relationships & 35 & $(14.6)$ \\
5. Find a faithful friend & 61 & $(25.4)$ \\
6. Family quarrels & 25 & $(10.4)$ \\
7. Hard Parent Duties & 48 & $(20)$ \\
8. Private affairs Interference & 19 & $(7.9)$ \\
9. Visiting Friends Weariness & 9 & $(3.8)$ \\
10. Parents Inappropriate & 15 & $(6.3)$ \\
treatment & 30 & $(12.5)$ \\
11. Many Home Duties & 41 & $(17.1)$ \\
12. Opinion Imposition & $1.81 \pm 2.154$ & \\
Mean \pm SD & &
\end{tabular}

Table 4. Prevalence of Psychological Problem as perceived by Nursing Students $(n=240)$.

\begin{tabular}{lll}
\hline Psychological Problems & N (\%)Frequency & (Percentage) \% \\
\hline 1. Hesitate Making Decisions & 114 & $(47.5)$ \\
2. Difficulty Focusing & 102 & $(42.5)$ \\
Attention & 114 & $(47.5)$ \\
3. Sharp with difficulties & 89 & $(37.1)$ \\
4. Desires Surrender & 98 & $(40.8)$ \\
5. Older Conversation Shame & $(12.9)$ \\
6. Low Self Confidence & 31 & $(14.2)$ \\
7. Nightmares & 34 & $(41.3)$ \\
8. Moody & 99 & $(34.6)$ \\
9. No Self Accountability & 83 & $(36.7)$ \\
10. Angered Quickly & 88 & $(12.9)$ \\
11. Isolation & 31 & $(7.5)$ \\
12. Suicidal Ideas & 18 & $(28.8)$ \\
13. Rapidly Affected by & 69 & $(52.5)$ \\
others & 126 & \\
14. Worry of Future & $4.57 \pm 3.300$ & \\
Mean \pm SD & &
\end{tabular}


Table (4) emphasizes that the most common psychological problems affecting university students were worry about future $52 \%$,hesitance in making decision \& Sharp with difficulties $47.5 \%$ followed by difficulty in focusing attention $42.5 \%$ and moody $41.3 \%$, shame from conversation $40.8 \%$, while overall psychological problems described as $4.57 \pm 3.300$ (Mean\& SD) on scale from 0 to 14 .

Table 5. Prevalence of Educational Problem as Perceived by Nursing Students $(n=240)$.

\begin{tabular}{lll}
\hline Educational Problems & $\begin{array}{l}\text { N } \\
\text { (\%)Frequency }\end{array}$ & (Percentage) \% \\
\hline 1. Lack Activities & 154 & $(64.2)$ \\
2. Difficulty Understanding Courses & 183 & $(76.3)$ \\
3. Lecturers Deal Rudely & 157 & $(65.4)$ \\
4. Difficulty Courses Registration & 135 & $(56.3)$ \\
5. Lectures Attending Time & 122 & $(50.8)$ \\
6. Difficulty Understand Lectures & 100 & $(41.7)$ \\
7. Large Student Numbers & 41 & $(17.1)$ \\
8. Lack Opportunity Meet Lecturers & 82 & $(34.2)$ \\
9. Low Academic Achievement & 116 & $(48.3)$ \\
10. Non Specialists Lecturers & 137 & $(57.1)$ \\
11. Advisor Dose not Perform & 87 & $(36.3)$ \\
Duties & 74 & $(30.8)$ \\
12. Lack Discipline Lecturers & 65 & $(27.1)$ \\
13. No Home Study Place & 112 & $(46.7)$ \\
14. Traditional Teaching Method & 168 & $(70.0)$ \\
15. Large Materials to Time & 127 & $(52.9)$ \\
16. Non Unified Materials & 121 & $(50.4)$ \\
17. Materials dose not met & 84 & $(35)$ \\
Ambitions & 64 & $(26.7)$ \\
18. Attendance mismatch grades & 124 & $(51.7)$ \\
19. Negative Education & 96 & $(40)$ \\
20. No Syllabus in the beginning & 148 & $(61.7)$ \\
21. Lecturer Absence & 148 & $(61.7)$ \\
22. Many Assignments & $11.07 \pm 5.549$ & \\
23. Plans Multiplicity & & \\
Mean \pm SD & 124 \\
\hline & & \\
\hline
\end{tabular}

Table (5)illustrates that overall educational problems which was $11.07 \pm 5.549$ (Mean \& SD) on scale from 0 to 23, while the most common educational problems the students suffering of, were difficulty understanding courses $76.3 \%$, followed by large materials to time $70 \%$, lacking activities $64.2 \%, 61 \%$ were many assignments and plans multiplicity, while the minority of the educational problems were large student numbers $17.1 \%$.

In table(6) The Pearson chi-Square indicate that there is a statistically significant relationship between level of psychological distress and gender and parental status. On the other hand, there is no relationship between level of psychological distress and course failure, residency, persons living with the student, or marital status of the students. The Pearson chi-Square results indicates that male and female are significantly different on their level of Psychological Distress Scale $(\mathrm{X} 2=15.356, \mathrm{df}=3, \mathrm{~N}=240, \mathrm{p}=0.01$ ), females are more likely to have higher level on psychological distress scale than male. Carmers V, which indicate the strength of the association between variables, is 0.253 and, thus, the effect size is considered to be medium. The Pearson chiSquare results indicates that students living with their both parents, separated parents, or lost at least one of their parents are significantly different on their level of Psychological Distress Scale $(\mathrm{X} 2=12.933, \mathrm{df}=6, \mathrm{~N}=240, \mathrm{P}=.044$ ), students with separated parents or lost at least one of their parents are more likely to have higher level on psychological distress scale than students living with their both parents.

Table (7) indicates that there is lack of difference between level of psychological distress and academic level, number of family members, and cumulative average. On the contrary, there is a significant relationship between level of psychological distress and number of children tau $(240)=.136$, $\mathrm{p}=.015$. Cramer's $\mathrm{V}=.179$ which indicate weak to moderate association between variables. This means that students with more number of children will have higher level of psychological distress.

As shown in table(8) the differences between group for average, social problems and educational problems are significant $(\mathrm{p}=0.01)$ while those for age are not.A statistically significant difference was found between students psychological distress scale (PDS) and social problems, $\mathrm{F}(3,2)=29.581, \mathrm{p}=.000$, and on educational problems, $\mathrm{F}(3,2)=24.960, \mathrm{p}=.000$.

Accordingly, students with higher educational and social problems have higher level of psychological distress level.

Table (9) A statistically significant difference of psychological problems level were found between male $(4.0917 \pm 3.40784)$ and female $(5.0583 \pm 3.13102)$ students, $F$ $(1)=5.236, p=.023$, that female students have higher level of psychological problems. A statistically significant difference of psychological problems level were found between student experience course failure during their study spectrum $(5.6200 \pm 3.45165)$ and students did not experiences course failure (4.3000 \pm 3.21364$)$ students, $F$ (1) $6.474, p=.012$, that student experience course failure during their study spectrum have higher level of psychological problems.

Student live with their relatives have higher level of psychological problems $(6.4783 \pm 3.04317)$, followed by students live with colleagues $(5.4615 \pm 4.23508)$, followed by students live alone $(4.7143 \pm 4.58138)$, while students live with their family have the lowest level of psychological problems (4.2620 \pm 3.07449$)$, with a statistically significant difference of psychological problems level were found between these groups, $F(4) 2.656, p=.034$. 
Table 6. Relationship Between Psychological Distress scale and nominal Socio-Demographic Characteristics as Perceived by Faculty students, using Pearson Chi-Square and Cramer's $V$.

\begin{tabular}{lll}
\hline & Pearson Chi-Square & Significance \\
\hline Gender & 15.356 & 0.002 \\
Course Failure & 4.464 & 0.216 \\
Residency & 2.446 & 0.485 \\
House Living/persons living with the student & 20.776 & 0.054 \\
Marital Status & 3.189 & 0.785 \\
Parental Status/Family Info & 12.933 & 0.044 \\
\hline
\end{tabular}

Table 7. Relationships between level of Psychological Distress and Ordinal Student's Socio-demographic Characteristics.

\begin{tabular}{lll}
\hline & Kendall's tau-b & Significance \\
\hline Academic Level & .043 & .443 \\
Number of family Members & .044 & .439 \\
Cumulative Average & -.036 & .511 \\
\hline
\end{tabular}

Table 8. Relationships between level of Psychological Distress \& Continuous Student's Socio-Demographic Variables Using one way ANOVA.

\begin{tabular}{|c|c|c|c|c|c|c|c|}
\hline & $\begin{array}{l}\text { Low } \\
\text { Mean } \pm \text { SD } \\
(\mathbf{N}=118)\end{array}$ & $\begin{array}{l}\text { Moderate } \\
\text { Mean } \pm \text { SD } \\
(\mathbf{N}=\mathbf{5 8})\end{array}$ & $\begin{array}{l}\text { High } \\
\text { Mean } \pm \text { SD } \\
(\mathbf{N}=\mathbf{2 8})\end{array}$ & $\begin{array}{l}\text { Very High } \\
\text { Mean } \pm \text { SD } \\
(\mathbf{N}=36)\end{array}$ & $\begin{array}{l}\text { Sig. Of Levene Test } \\
\text { of Homogeneity of } \\
\text { Variance }\end{array}$ & $\mathbf{F}$ & Sig. \\
\hline Age & $21.78 \pm 4.025$ & $21.83 \pm 2.927$ & $21.54 \pm 2.701$ & $21.94 \pm 3.098$ & .517 & .097 & .962 \\
\hline Social problems & $.97 \pm 1.113$ & $1.98 \pm 2.048$ & $1.71 \pm 1.675$ & $4.36 \pm 3.072$ & .000 & 29.581 & .000 \\
\hline Educational Problems & $8.61 \pm 5.011$ & $12.00 \pm 4.679$ & $13.25 \pm 3.768$ & $16.09 \pm 5.371$ & .223 & 24.960 & .000 \\
\hline
\end{tabular}

Table 9. Significant Relationships between Psychological Problems and Student's Socio-demographic Variables using one way ANOVA.

\begin{tabular}{|c|c|c|c|c|}
\hline & Psychological Problems Mean & Sig. Of Levene Test of Homogeneity of Variance & $\mathbf{F}$ & Sig. \\
\hline Gender: Male $(\mathrm{N}=120)$ & $4.091 \pm 3.40$ & \multirow[t]{2}{*}{ 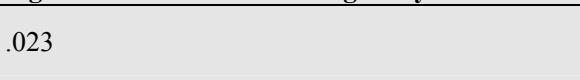 } & \multirow{2}{*}{5.236} & \multirow{2}{*}{.023} \\
\hline Gender: Female $(\mathrm{N}=120)$ & $5.05 \pm 3.131$ & & & \\
\hline Course Failure: Yes (N=50) & $5.62 \pm 3.45$ & \multirow{2}{*}{.292} & \multirow{2}{*}{6.474} & \multirow{2}{*}{.012} \\
\hline Course Failure: No $(\mathrm{N}=190)$ & $4.30 \pm 3.21$ & & & \\
\hline Live with family $(\mathrm{N}=187)$ & $4.26 \pm 3.074$ & \multirow{5}{*}{.115} & \multirow{6}{*}{2.656} & \multirow{5}{*}{.03} \\
\hline Live with relatives $(\mathrm{N}=23)$ & $6.47 \pm 3.04$ & & & \\
\hline Live with colleagues $(\mathrm{N}=13)$ & $5.46 \pm 4.23$ & & & \\
\hline Live alone $(\mathrm{N}=14)$ & $4.71 \pm 4.58$ & & & \\
\hline Others $(\mathrm{N}=3)$ & $5.00 \pm 4.58$ & & & \\
\hline No Children $(\mathrm{N}=100)$ & $4.11 \pm 3.29$ & \multirow{3}{*}{.489} & & \multirow{3}{*}{.025} \\
\hline $1<3(\mathrm{~N}=136)$ & $4.84 \pm 3.16$ & & \multirow[t]{2}{*}{2.456} & \\
\hline$<3$ children $(\mathrm{N}=4)$ & $4.50 \pm 3.52$ & & & \\
\hline
\end{tabular}

\section{Discussion}

Psychological distress among higher education nursing students is of global concern. Students are exposed to additional stressors which may further increase their risk for psychological distress. The ways in which these students cope with distress has potential consequences for their health and academic performance. This study was aimed to determine the psychosocial and educational problems for undergraduate nursing students.

Concerning of socio demographic characteristics for nursing student the present study revealed that about less than half percentage of the study sample were from third year students, while one third percent of them were from second year followed by less than quarter percent were from fourth year .Moreover, regarding to course failure it was found that, approximately less than quarter percent of them had previous failure in the course. In relation to residency of the students, it was found that, more than thirty percent of the study sample was live outside their city this finding was supported by Caldwell. JC et al(2003) who study that young people who live with their parents are less likely to have emotional problems , and that their behavior is more likely to be under their parents control. Secure attachment during adolescence is related to fewer mental health problems ,including lower levels of depression, anxiety and feelings of personal inadequacy (Lessard \& Moretti 2008).

Concerning with students were live with their families it was found that more than three quarter percent of the students live with their families while less than one tens of them were live with their relatives and their colleagues $(5.4 \%)$ and alone (5.8\%), these results was congruent with Abeba Bekele( 2006)who found that, one hundred eighty-two students living alone reported feeling sad or hopeless almost every day or more and they stopped doing their usual activities and those with friends and relatives being more likely to have the symptom in relation to students family connectedness.

It was found that, more than three quarter of students, their family was connected to each other while less than ten percent from families of students were divorced followed by $(13.8 \%)$ of them were widows. This is in agreement with a study done by Sandi, Rebecca\&, Gregory, (2001) who found that, Students living with both biological parents were 
generally exhibit the lowest rates of psychological problems and better than their counterparts living with one parent only, friends or alone. Specifically the analysis of the relationship between teenagers' living arrangements and depressive symptoms in this study shows that teenagers living with both biological parents have the most favorable outcomes.

As regards level of Psychological Distress Scale for both male and female it was found that there are statistically significantly different on their level of Psychological Distress Scale that females are more likely to have higher level of psychological distress scale than male these results were supported by study of (Hamann and Canli,2007) that individual differences in stress reactivity have been proposed as a potentially important risk factor for gender-specific health problems in men and women, in addition to genetic, socio-cultural, hormonal and developmental factors this is consistent with a study done by Michelle Lynne Charleston and Jennifer (2002) who stated that cognitive style more common in female than male that increases the risk for depression is ruminative thinking repetitively and passively focusing on symptoms of distress.

It has been proposed that female are more likely to be negatively affected by interpersonal events than men. These differences in experimental findings and alternative theoretical models highlight the complex nature of the gender-specific stress response, which may be dependent on the type of stressor/challenge, experimental procedure, outcome measured and subject status (Kenny\& Donaldson, 2010)

Regarding students social problems among students with their parents it was found that, of less than half percent of students have problems in their relation with parents followed by difficulties in finding faithful friends. Moreover less than quarter percent of students suffering from hard parent's duties and less than fifteen percent of them find difficulty in building relationship with other colleges. These finding were supported by (Dusselier et al., 2005) who stated that stress is a mechanism of any internal or external demand made upon the body and considered as a state that results from interaction of individual with environment that is perceived by threat to their well-being. Elliot and Gramling (1990) found that social support helps the college students to lessen depression, anxiety, and stress. They also found that social support could help the students manage and lessen their psychological problems.

According to psychological problems of undergraduate nursing students the present study found that above half percent of students were worry about their future and less than half percent of them have psychological problems including hesitate in making decision, sharp with difficulties, difficulty in focusing attention ,moody, and shame during conversation, these results were supported by Eskin (2003)who mentioned that students have psychological problems because of they want to make friends ,social support is very important for individuals in their life. Deficits in social support have been shown to be related to many psychological problems such as depression, loneliness, and anxiety.

As regards students living with their both parents, separated parents, or lost at least one of their parents the present study found that there are significantly different on their level of Psychological Distress Scale. Students with separated parents or lost at least one of their parents are more likely to have higher level of psychological distress than students living with their both parents. These finding was congruent with Calvete\& Connor-Smith, 2006) that mentioned that parenting produce independent and functioning adult and parent role for their children in college changed to become advisory to provide lots of support, encouragement, and accountability. Moreover, these results were consistent with findings done by (Blum \& Rinehart, 2007) that having a intact family connectedness was found to be protective against depressive symptoms and suicidal thought. As most of the participants mentioned in the group discussions that less secure attachment to parents may contribute to the development of depressive symptoms among young adolescents.

A study done by (Yang shengyong, 2006) found that the burden of psychosocial concerns including depressive symptoms, suicidal ideation and suicide attempt is high among group of youth .It further indicated the presence of several factors that predict depressive symptoms and suicidal ideation. Living with both biological parents and good parent-teen connectedness are also related to better psychosocial health.

Concerning of relation between academic achievement and level of psychological distress among university students, it was found that, no significant relation was found between academic achievement and level of psychological distress among university students. Our results were contradicted with (Williamson, Birmaher, Ryan, and Dahl (2005).These were conducted that psychological problems, i.e., depression, anxiety, and stress do have influence on the academic achievement of the students and reported that stressful life events are significantly elevated in anxious and depressed youths, thus could lead to low performance in academic.

The current study results were incongruent with (Vogel \& Collins, 2006) those study the level of psychological problems of the students in relation to their academic achievement. According to their finding, students who have high depression tend to perform poorly in academic performance compared to those with low depression. Similarly, students with high anxiety level and high stress level also do not do well in their academic performance. These studies support the idea that the level of psychological problems of the students does affect their academic performance .According to Porter (2005), up to $60 \%$ of university students left university without finishing their degrees due to inability to manage these psychological conditions, Steinberg and Darling (2005) reported that these psychological conditions for students contributed to poor grades in courses.

According to student course failure, it was found that, student who failed in the courses during their study have 
higher level of psychological problems. Nelson, Benner, Lane, \& Smith, (2004) has demonstrated that, students with severe behavior problem experienced academic deficits as compared to typical peers. Students with learning disabilities (LD) often have problems that go far beyond those experienced in reading, writing, math, memory, or organization. For many, strong feelings of frustration, anger, sadness, or shame can lead to psychological difficulties such as anxiety.

Psychological condition of the students is very much crucial to be reviewed and studied. This is because students who are psychologically stable can perform well in academic life. In other words, those who are experiencing psychological problems such as depression, anxiety and stress may face problems in managing their academic performance .Psychological stability is indeed an important predictor that could contribute to high academic achievement.

\section{Conclusion}

The present study concluded that females are more likely to have higher level of psychological distress feeling than male students there is a statistically significant relationship between level of psychological distress, gender and parental status. Students with separated parents or lost at least one of their parents are more likely to have higher level of psychological distress than students living with their both parents. Moreover the most common psychological problems affecting university students were worry about their future, hesitance in making decision, difficulty in focusing attention, moody, and shame from conversation

\section{Recommendation}

1- Further researches are needed on teaching and evaluation strategies which use a deliberate caring perspective especially for student nurses.

2-Particular attention must be given to barriers which prevent faculty nursing students from educational achievement and early interventions to prevent the development of psychological problems for university students.

3-Analysis and resolution of conflict problems in nursing education that can contribute to a sense of hopefulness and satisfaction in the teaching and learning of nursing.

4-Current programs were needed to minimize the high levels of psychological stress evidenced here particularly in relation to workload for university nursing students

5-In the future, the research should implement the study on large sample from different faculties within Cairo university.

\section{References}

[1] Abebe G/M. (2001) Health and psychosocial problems of school adolescents in Jimma zone, southwest Ethiopia. Ethiop J. Health Dev.; 15(2):97-107.
[2] Andrews, G., \& Slade, T (2001). Interpreting scores on the Kessler Psychological Distress Scale (k10). Australian and New Zealand Journal of Public Health, 25, 494-497.

[3] Blum, R.W., \& Rinehart, P.M. (2007). Reducing the risk: Connections that make a difference in the lives of youth. Division of General Pediatrics and Adolescent Health, University of Minnesota. Minneapolis, USA.40,

[4] Caldwell. JC et al, (2003).African families and AIDS:Context, reactions and potential interventions, Health Transition Review, 3(Suppl): 1-16.

[5] Calvete, H. \& Connor-Smith, J.K. (2006). Perceived social support, coping, and symptoms of distress in American and Spanish students. Anxiety, Stress, and Coping, 19(1), 47 - 65.

[6] Department of Statistics, Ministry of Education (2007). Retrieved July 20, 2008, from http://www.edu.tw/statistics/

[7] Dollete, Steese, Phillips, Matthews, (2004): Understanding girls' circle as an intervention on perceived social support, body image, self-efficacy, locus of control and self-esteem. The Journal of Psychology, 90 (2), 204215.

[8] Dusselier, L., Dunn, B., Wang, Y., Shelley, M. C., \& Whalen, D. F. (2005): Personal, health, academic, and environmental predictors of stress for residence hall students. Journal of American College Health. 54: 15-24.

[9] Elliot, T.R., \& Gramling, S.E. (1990): Personal assertiveness and the effects of socialsupport among college students. Journal of Counseling Psychology, 37,427-436.

[10] Eskin, M. (2003): Self-reported assertiveness in Swedish and Turkish adolescents: A cross-cultural comparison. Scandinavian Journal of Psychology, 44, 7-12.

[11] Gurung, R.A.R (2006): Health Psychology: A Cultural Approach. Belmont CA: Thomson Wadsworth.

[12] Hamann and Canli :( 2007) Gender difference in neural response to psychological stress.

[13] Kadison R, \& DiGeronimo TF.( 2004) College of the overwhelmed: The campus mental health crisis and what to do about It. San Francisco: Jossey-Bass.

[14] Kenny ME, \& Donaldson GA.( 2010) Contributions of parental attachment and family structure to the social and psychological functioning of first-year college students. Journal of Counseling Psychology,38, 479-486.

[15] Kessler . R \& D Mroczek. (1994).Final Versions of our NonSpecific Psychological Distress Scale [Written communication - memo dated 10/3/94]. Ann Arbor (MI), Survey Research Center of the Institute for Social Research, University of Michigan,.

[16] Lakey, B., \& Cohen, S. (2000): Social support theory and measurement. In Cohen, S., Underwood, L. G., \& Gottlieb, B. H. (Eds.), Social support measurement and interventions: A guide for health and social scientists. New York: Oxford.

[17] Lessard JC, \& Moretti MM. (2008). Suicidal ideation in an adolescent clinical sample: Attachment patterns and clinical implications. Journal of Adolescence; 21, 383-395.

[18] Michelle C, Lynne F.G, Charleston B and Jennifer P., (2002).Correlates of attempted suicide among youth living in Indian reservations in Mexico. The 130 Annual Meeting of APHA. 
[19] Nelson, J.R., Benner, G. J., Lane, K. \& Smith, B. W. (2004). Academic achievement of K-12 students with emotional and behavioral disorders. Exceptional Children, 71(1), 59-73.

[20] Rob, S.Callahan, N.(2011).Undergraduate completion and persistence at four-year colleges 31. and universities. National Institute of Independent Colleges and Universities.

[21] Royal College of Psychiatrists: (2003).The mental health in students in higher education. London: Royal College of Psychiatrists.

[22] Sandi N, Rebecca L.C, Gregory A, (2001). How teenagers fare in cohabitating couple and blended families. Beyond the twoparent family. Number B-31 inSeries, 'New Federalism: National Survey of America families.

[23] Solomon S. Mesganaw F. \&, Abeba B. (2006) Psychosocial problems among students in preparatory school, in Dessie town, north east Ethiopia .

[24] Steinberg, L, \& Darling, N. (2005). The broader context of social influence in 42. adolescence. In Silbereisen, R.K. \& Todt, E. (Eds.), Adolescence in Context: The Interplay of
Family, School, Peers, and Work in Adjustment. New York: SpringerVerlag Inc.

[25] Tao, S., Dong, Q., Pratt, M. W., Hunsberger, B., \& Pancer, S. M. (2007). Social support: Relations to coping and adjustment during the transition to university in the Peoples Republic of China. Journal of Adolescent Research, 5(1), 123-144.

[26] Villanova, P. \& Bownas, D.A. (2008). Dimension of college student of the Southeastern.

[27] Vogel, H. \& Collins, A. (2006). The relationship between test anxiety and academic performance. Journal of Abnormal and Social Psychology. 67: 523-532.

[28] Williamson, D.E., Birmaher, B., Ryan, N.D., \& Dahl, R.E. (2005). Stressful life events in anxious and depressed children. Journal of Child and Adolescent Psychopharmacology. 15(4): 571-580.

[29] Yang shengyong. (2006), Causes to Produce University students psychological Crises and the Countermeasures[J]. Journal of Guizhou Ethnic Institute (Philosophy and Social Science Edition),4p150 1037. 